This item is the archived peer-reviewed author-version of:

Much Ado About Nothing? The low importance of Twitter as a sourcing tool for economic journalists

\title{
Reference:
}

Johnson Michiel, Paulussen Steve, Van Aelst Peter.- Much Ado About Nothing? The low importance of Tw itter as a sourcing tool for economic journalists Digital journalism - ISSN 2167-0811 - 6:7(2018), p. 869-888

Full text (Publisher's DOI): https://doi.org/10.1080/21670811.2018.1490657

To cite this reference: https://hdl.handle.net/10067/1534020151162165141 


\section{Much Ado About Nothing?}

The low importance of Twitter as a sourcing tool for economic journalists

\section{Authors}

Michiel Johnson, Department of Communication Studies, University of Antwerp, Belgium. E-mail: michiel.johnson@ uantwerpen.be (corresponding author)

Steve Paulussen, Department of Communication Studies, University of Antwerp, Belgium.

E-mail: steve.paulussen@uantwerpen.be

Peter Van Aelst, Department of Political Sciences, University of Antwerp, Belgium.

E-mail: peter.vanaelst@uantwerpen.be

\section{Funding}

This research was supported by the Research Foundation - Flanders [grant number G032614N] 


\begin{abstract}
Digitalisation has changed journalistic sourcing techniques and affected the way journalists approach sources. This study examines how new information channels change the relationship between journalists and their (potential) sources in this evolving environment and analyses the role of these channels. We are not only interested in the sources that make it into the news, but study the broader networks of people and institutions journalists rely on to help them monitor and gather information. We combine online Twitter network analysis with in-depth interviews to create a detailed mapping of the professional source networks of 33 economic journalists in Belgium. Our results identify that the Twitter networks of economic journalists to a large extent reflect their broader sourcing practices. Overall the same actor groups are important in both the online and the offline source networks with the exception of the more prominent presence of other journalists and media organisations in the Twitter network of journalists. We conclude that Twitter is implemented within existing sourcing practices without fundamentally changing the news production process.
\end{abstract}

Keywords: sourcing, economic journalists, Twitter, source networks, social media 


\section{Introduction}

Research suggests that while journalists' uses of Twitter may differ widely, the social media platform influences both their online and offline sourcing practices (Gulyás 2013; Hedman and Djerf-Pierre 2013). As Twitter is considered as a useful tool by a majority of journalists to monitor news and information (Broersma and Graham 2016; Hedman and Djerf-Pierre 2017), we can expect that this affects the processes of information gathering and news selection. More specifically, we assume that journalists' monitoring of Twitter will not only affect the actors whom they consult and use as sources in their news reports, but it may also influence and shape their broader perceptions of the importance of different source actor groups. To investigate these assumptions, this study poses two questions: (1) What functions does Twitter serve in journalists' sourcing practices?, and (2) How do journalists' uses of Twitter as a sourcing tool compare to their actual sourcing behaviour?

The study uses in-depth interviews with 33 economic journalists working for print news media in Flanders, the northern part of Belgium. First, we analyse the Twitter networks of these journalists, i.e. the organisations and people they follow on the social media platform. Through the interviews, we aim to investigate to what extent these Twitter networks reflect their broader online and offline sourcing practices in their daily work. In addition, the interviews give us a deeper insight into the journalists' perceptions about the importance of different source actor groups and about the role of Twitter as a sourcing tool. By combining and comparing findings from the Twitter network analysis with the journalists' actual sourcing behaviour and their own perceptions as reported in the interviews, we aim to arrive at a better understanding of journalists' sourcing behaviour in a changing news environment.

Our results identify that the Twitter networks of economic journalists to a large extent reflect their broader sourcing practices. In both the online and the offline source networks, traditional elite sources remain omnipresent, with only a very small group of active Twitter users including more bottom-up sources in their online networks. The most important difference is the more prominent presence of other journalists and media organisations in the Twitter network of journalists. This is in line with the finding that Twitter is mainly used as a monitoring tool that can operate as a source of inspiration and/or an actual trigger for news stories.

\section{Defining sources}

In Deciding what's news, Herbert Gans $(1979,80)$ described sources as "the actors whom journalists observe or interview, including interviewees who appear on the air or who are quoted in magazine articles and those who only supply background information or story suggestions". Following this definition, we also conceptualise sources as human actors, i.e. as individuals or as organisations that group these individuals such as political parties, companies or civil society organisations. This means that the term 'sources' does not refer to information channels, but only to the actors that use these channels to offer information that can reach journalists. A distinction between sources and channels was also made by Sigal (1973), who defined the latter as "the paths by which information reached the reporter" (Sigal 1999, 225). Although we are aware that in today's digital news environment, the lines between actors and channels are blurring to an extent that it may even become useful to also conceptualise non-human entities, such as Twitter, as 'actants' - i.e. technological devices that have 'agency' (see e.g. Reich and Barnoy 2016) - we persist in separating actors from channels. An important argument here is that information can always be traced back to the 
actor that provides the information. This is not to say, however, that the channel doesn't matter. On the contrary, we assume that the technological affordances of the information channel through which this process occurs, may influence the hierarchy between source actors. The question, then, is whether Twitter - as a channel - enables certain sources - as actors - to increase their access to the news at the expense of other actors. Here, the concept of 'potential sources' (see Deprez and Van Leuven 2017; Van Leuven and Deprez 2017) becomes important, since the profiles journalists follow on Twitter can tell us more about the actors they consider as potentially relevant sources for their work and their sourcing habits. We therefore address a journalist's Twitter following list as a network of 'potential sources', which may partially overlap with their 'actual sources'. With actual sources we refer to the actors that journalists use to make a concrete news item.

Another idea we take from the definition of Gans (1979) is that sources as actors can serve different functions for journalists; they can be quoted and explicitly used in news stories, but they can also be consulted for background information or as generators of new story ideas. As Reich $(2009,36-39)$ argues, it is important to understand journalistic sourcing as a process that consists of at least two phases. In the 'news discovery' phase, journalists become aware of the existence of a potential news item. The word 'potential' is crucial here, since not every lead found in the discovery phase generates an article. In the 'news gathering' phase, more information on promising leads is collected to uncover the whole story or to verify discoveries. Research on the role of Twitter in journalism suggests that the social media platform seems to be especially useful in the news discovery phase to monitor information streams and keep an eye on 'potential' sources or to look for background sources (Gulyás 2017; Hedman and Djerf Pierre 2017). Hence, studies on the influence of social media on journalistic sourcing practices should not only focus on the sources that make it into the news stories, but should also try to include the sources contacted in the preparatory news discovery phase. In sum, we define sources as actors that convey information that can reach journalists through different channels at both the discovery and gathering phases of the news production process.

\section{The role of Twitter in journalistic sourcing}

Several studies have already analysed the role of Twitter and social media in the sourcing process. Through content analyses, researchers have examined the appearance of social media, particularly Twitter, as cited sources in the news (Broersma and Graham 2013; Hladík and Štettka 2017; Paulussen and Harder 2014). These studies found that even though there is an increase of social media references in traditional media, their presence in the news remains rather small because journalists seem to turn to social media only to cite source actors who are not readily available other than on these platforms (Broersma and Graham 2013; Paulussen and Harder 2014). Overall, the content analyses do not support the assumption that social media would have enabled non-elite sources, such as citizens, to increase their visibility and access to news stories (Hladík and Štětka 2017; Lecheler and Kruikemeier 2016). However, content analyses focus on the finished news product, and only take into account those source actors that have passed the gates of journalistic source selection. This may lead to an underrecognition of the idea that social media are primarily used for monitoring purposes, to follow debates and public opinion in an online setting (Broersma and Graham 2016; Hedman and Djerf-Pierre 2017). The notion of Twitter as an online social awareness system that provides journalists with information in the news discovery phase may be underestimated in studies that are based on content analysis.

Compared to content analyses, survey research provides a broader insight into journalists' uses and perceptions of social media in their daily work. Based on a review of 
survey research on social media uses among journalists, Hedman and Djerf-Pierre (2017) conclude that despite a diverse use of Twitter by journalists, there are overall three uses of Twitter that can be identified: branding, networking and researching. Within this last use, they mainly see Twitter as a tool for journalists to constantly monitor information (Broersma and Graham 2016; Hedman and Djerf-Pierre 2017). We should keep in mind that Twitter remains a single information channel in competition with various other channels of information (Raeymaeckers et al. 2015). Nonetheless, Twitter is considered a relevant channel in the news discovery phase, especially since journalists can construct their own network and consequently their individual stream of information. In this sense, journalists build an awareness system that has the potential to constantly update them on relevant information (Hermida 2010).

Broadly speaking, we can thus make two observations regarding the role of Twitter as a journalistic sourcing tool. On the one hand, content analyses of news output suggest a rather modest influence of social media in the end-product of the news production process. Survey research, on the other hand, describes the platform as a monitoring tool and unveils its relevance in the news discovery phase. Little research exists that links the latent functions of social media in the news discovery phase with the manifest appearance of social media references in the news content, that is, as an outcome of the news gathering phase. Reich (2009) tried to tackle this gap between latent and manifest functions by using reconstruction interviews to uncover journalists' decisions in the different phases of source selection. While his research focuses on journalists sourcing habits in general, the present study will use interviews to examine how sourcing practices may be affected by the rise of Twitter as a new (potential) information channel for journalists. To date, research on Twitter and journalism based on interviews has been occupied with analysing how social media urge journalists to renegotiate their professional role and values in the digital environment (e.g. Zeller and Hermida 2015), or how journalists use Twitter as a tool for purposes of organisational marketing and personal branding (e.g. Tandoc and Vos 2016; Brems et al. 2016). This study uses interviews to investigate the functions of Twitter in the daily sourcing practices of journalists.

\section{Sourcing in economic journalism}

Since the creation of Twitter, scholars have been interested in how journalists use this medium as a sourcing tool in their work. Most studies concentrate either on journalists in general (e.g Hedman and Djerf-Pierre 2013; Gulyás 2013) or on political journalists in particular (e.g. Broersma and Graham 2012; Lawrence et al. 2014; Parmelee 2013). More occasionally, researchers have looked at Twitter sourcing practices of specialised journalists, like sports journalists (Deprez, Mechant and Hoebeke 2013) or health journalists (Deprez and Van Leuven 2017). Few studies have been done on the use of Twitter by economic journalists. Lariscy and colleagues investigated the use of social media among 200 financial/business journalists in the United States, showing that Twitter was not highly used as a source in this news beat (Lariscy et al. 2009). This finding might be due to the fact that Twitter in 2008 was a new platform that was not really integrated in journalists' work habits. Therefore, we question whether their 'minimal influence' conclusion still holds today.

In recent years, the scholarly attention for economic journalism is growing (Kjær and Slaatta 2007; Lee 2014). Especially the financial crisis in 2008 has boosted the interest in this issue among both researchers (Lee 2014; Schiffrin 2015) and the general public (Schifferes and Coulter 2013). The emerging body of literature, however, focuses mainly on this financial crisis and studies different aspects of the economic breakdown, such as the failing role of the 
economic press as watchdog (Kalogeropoulos, Svensson et al. 2015; Manning 2013; Schiffrin 2015).

Studies that analysed the news coverage right before and during the crisis show that a narrow range of elite financial sources dominate the news (e.g. Berry 2013; Knowles, Gail and Lindberg 2017; Manning 2013). This is in line with earlier research indicating that a small range of elite sources dictate the economic news beat (Durham 2007). Economic journalists work in an environment of complex information and therefore often rely on familiar sources (Tambini 2010), with the majority of ideas originating from a routine flow of corporate and economic news releases combined with other media sources (Doyle 2006). This phenomenon is also present within other newsbeats, since professional journalists' routine of relying on a specific network of sources whom they deem relevant and credible, is a constitutive part of the epistemology of journalism (Ettema and Glasser 1985; Ekström 2002). Within journalists' network of sources, official sources, such as government officials, politicians and business actors are more likely to be considered as authoritative and suitable (Gans 1979; Sigal 1973; Reich 2009). In the digital age, the 'elite bias' and prevalence of institutional sources in the news is frequently questioned, since new platforms such as Twitter provide new and easier ways to contact sources. Furthermore, Twitter also allows to devote more attention to non-elite actors, such as ordinary citizens, perhaps not as prominent sources in the news, but rather as a more indirect or background source to get inspiration for stories or a better idea of what the public is concerned about. It is therefore needed to study these sourcing practices in a new media environment concentrating on day-to-day economic coverage. Especially since exposure to economic information in the media influences and enhances the economic sophistication of the audience, particularly in a frame that presents the economic consequences of certain events (Kalogeropoulos, Albæk et al. 2015).

\section{Research questions}

The goal of our empirical study is two-fold. First, we are interested in the role of Twitter within the news production process. Therefore, we try to uncover how their Twitter usage compares to and affects traditional news gathering routines. This leads us to the following research question:

RQ1: How do economic journalists perceive the functions of Twitter as a sourcing tool in the discovery and gathering phases of the news production process?

Secondly, we are interested in the source networks of journalists. To fully grasp this network of sources, we try to identify all source actors that journalists encounter in both the news discovery and news gathering phase, both online and offline. We analyse journalists' Twitter networks and compare them with their actual sourcing behaviour. This comparison will allow us to answer our second research question:

RQ2: How does the Twitter network of potential sources of economic journalists compare to their actual sourcing behaviour?

\section{Methodology}

To answer these two research questions, we combine data about the journalists' Twitter networks with insights gained from in-depth interviews with the same journalists. The interviews allow us to dive into the contacts whom journalists encounter, potentially 
influencing their news selection decisions. We also examine journalists' perceptions of the importance of these sources in their daily work.

In total, we interviewed 33 economic journalists working for print media in Flanders, the northern, Dutch-speaking part of Belgium. We identified these journalists using the database of the Flemish association of professional journalists (VVJ), which contains information about all Flemish professional journalists in possession of a press card. Initially, we selected all journalists who were included in the news beat category of economic or financial news. This sampling procedure resulted in a list of 77 economic journalists of whom 60 had a public Twitter account. We contacted these 60 journalists for an interview and 33 of them agreed to participate in our study. The interviews with these 33 journalists took place between May and October of $2016^{1}$. Nineteen of the interviewed journalists work for a newspaper, of whom 12 for a business newspaper and 7 for a general newspaper; 12 journalists work for a news magazine, one for a news website and one interviewee is a freelancer. Although all of the interviewees maintained a personal Twitter account, their Twitter activity varies significantly (see Appendix for an overview of the journalists and their number of tweets, followees and followers).

Before the interviews, we analysed the Twitter profiles of the 33 economic journalists in our sample. We used a one-degree ego network analysis approach to investigate the contacts they connect with online. The construction of ego-networks starts from one central node in the network - in our study the journalist - who is connected to all the other nodes in the network - the source actors consulted by the journalist. We study these networks to the first degree because we are only interested in the relations between the journalists and their sources, not between the sources themselves. We collected the followees (i.e. the accounts followed by the journalist) of the journalists using the software tool NodeXL during a fivemonth period from the 1st of April 2015 until the 31st of August $2015^{2}$. The followees were subsequently coded into seven different actor groups: business professionals, media and journalists, experts and academics, politicians and government, civil society and interest groups, citizens and other (e.g. celebrities or parody accounts). The collected data give us an indication of the actors whom they consider as worthy to follow and who can be regarded as direct 'potential sources' in the journalists' Twitter networks (see also Deprez and Van Leuven, 2017; Van Leuven and Deprez, 2017).

In a second phase, we conducted computer-assisted in-depth interviews with each of the 33 journalists in our sample. As said above, these interviews took place between May and October of 2016. Although there is a time lag of about one year between the analysis of the Twitter networks and the interviews, the journalists indicated that their Twitter networks remained quite stable overtime. Journalists were presented with survey questions on a tablet in a face-to-face setting. The survey was constructed in the Graphical Ego-centred Network Survey Interface (GENSI) developed by Stark and Krosnick (2017). This tool is designed to facilitate the questioning of ego-centred network data and to implement this network module in a larger questionnaire. We used it mainly to get a better insight in the actual sourcing practices of journalists. For the data collection of their sources, we base ourselves on the idea of the one-degree ego networks we constructed on Twitter and apply a similar network approach. This means that we start from the journalist as a central node and ask which sources they used in the last week prior to the interview. This provides us with multiple types of sources, but of course not with the complete network of sources. In network surveys the respondents are usually asked to list their contacts - here sources - in 'name generator' questions and afterwards report the attributes of these different contacts in 'name interpreter' questions. The GENSI tool provides an immediate graphic representation of this ego-network with the journalists in the middle and the given sources around this central node and allows us to ask follow-up questions about all the contacts at once (Stark and Krosnick 2017). Figure 1 
shows an example question of the survey where the journalist was asked to classify the 11 sources named as either background information or as a source mentioned in a specific news report.

Not only the visualisation is an important feature; a study by Stark and Krosnick (2017) also shows that the use of the tool leads to a more positive evaluation of the questionnaire as compared to other online social network analysis tools.

\section{Figure 1: Example question of the Graphical Ego-centred Network Survey Interface}

Drag the different sources to the appropriate box and classify them in sources used as background information or sources in the news.

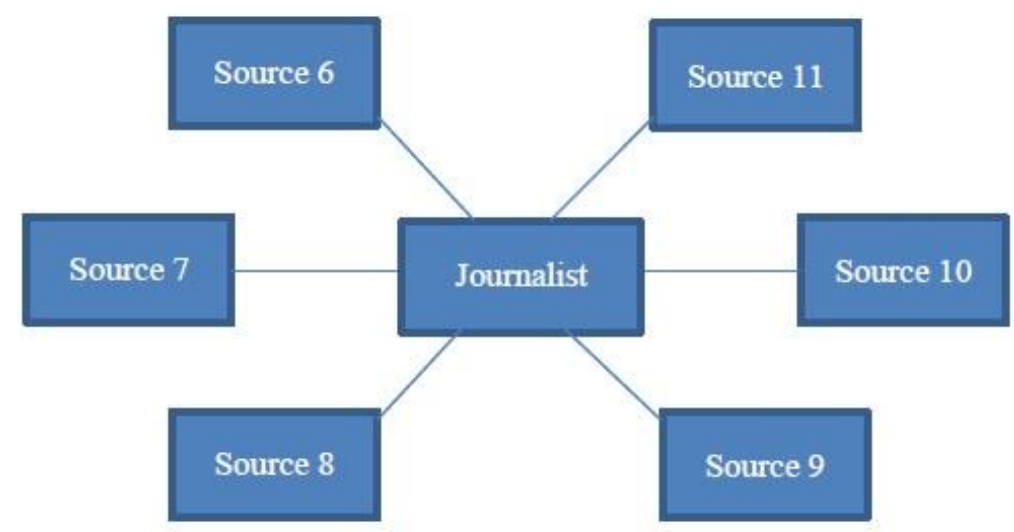

Background information

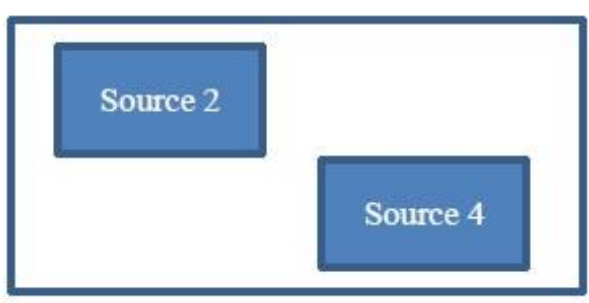

Source in the news

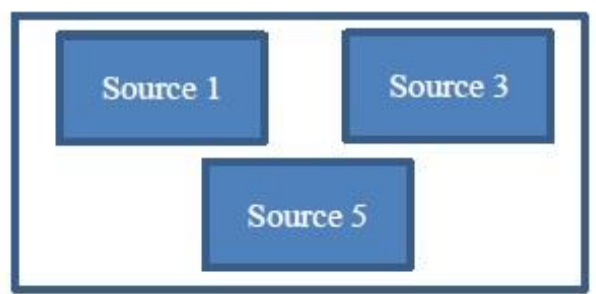

Note: this is not the lay-out of the actual GENSI-survey but a recreated figure

The closed questions in this tool were combined with open-ended questions, posed by the interviewer, which provided us with additional information on how and why certain sources were used and how important they are perceived to be. This led to qualitative interview data that both complements and enriches the quantitative data from the survey questions.

In the interviews we asked four types of questions. First, we discussed the importance of different actor groups with the journalists and their frequency of contact with them. This provided us with a general understanding of the relevance of these different actor groups.

Second, to collect information on their actual sourcing behaviour, we asked journalists to reconstruct the sources whom they had contacted in the work week prior to the interview. We explicitly stated that we were not only interested in the sources that they had cited or mentioned in their news articles, but in every person or organisation from whom they had 
retrieved (background) information that helped them write their news stories in that week. It was also clarified that we meant by information any piece of published (articles, reports, emails, social media posts, ...) or spoken information (e.g. gathered through a telephone call or interview). The average number of sources listed was ten, with a maximum of 18 and a minimum of five. While these numbers may seem quite low, we should keep in mind that our sample includes both newspaper and magazine journalists, and the interviewees in our sample wrote, on average, six articles in the week prior to the interview.

Third, the interviewees were asked four follow-up questions about the sources they named. We first inquired whether the source actor was an explicit source in the news or contacted for background information. Secondly, we evaluated the frequency of contact with the source actor. Thirdly, we asked them how they regularly contacted these sources, that is, which information channel they used to consult the source. Finally, we inquired if they followed the source actor on Twitter or not.

The fourth and final part of the interview contained several questions on social media use and the influence of these new tools on their work. Here, the journalists assessed different characteristics of Twitter use on a 4-point Likert scale ranging from 'totally disagree' to 'totally agree'. These survey questions give us an insight in the importance and relevance of Twitter and social media in general.

Afterwards, the sources studied were coded into the same six actor groups that were used to classify the followees in the journalists' Twitter network (leaving out the 'other' category). In total, the 33 journalists mentioned 329 source actors, of whom 327 could be coded into the actor groups; the two remaining sources were confidential. Since we define sources as being actors, published reports or articles were recoded into the source actors they originate from: e.g. if a journalist said to have consulted a press release by a company, it was the company (source actor) and not the press release (channel) that we considered as the source.

In sum, the methodology we used provides us with three different types of data on source actors. First, we mapped their online Twitter networks of potential sources. Secondly, the GENSI survey questions provided us with quantitative data on the actual sourcing practices and source networks of the journalists. In addition, the interviews also invited the journalists to share their own views and perceptions about the importance of different source actor groups and the role of social media in their daily work. These qualitative data allow us to interpret the findings obtained through the Twitter analysis and survey questions.

\section{Results}

To answer the first research question, we look at the use of Twitter and discuss the perceptions of the different functions of Twitter in the news production process. Next, to address the second research question we compare the Twitter networks of the economic journalists with their actual sourcing behaviour. Here we discuss the presence of the different actor groups and examine the overlaps and differences between their Twitter network of 'potential sources' and their actual source network. Finally, we further analyse the journalists' actual sources and their perceived importance.

\section{The functions of Twitter as a sourcing tool}

The 33 journalists in our sample display a very broad use of Twitter, with tweets, followees and followers being very widespread, as shown in Table 1 (see Appendix for a complete overview). Their Twitter profiles, however, were all mainly used for professional purposes. Only two journalists indicated that they also used Twitter in a private context. On average, an 
economic journalist in our sample follows more than 500 other people or organisations on Twitter. This suggests that Twitter at least potentially can play a role in the sourcing process of the journalists in our study.

Table 1:Descriptives on the number of tweets, followees and followers of the Twitter profiles of economic journalists $(\mathrm{N}=33)$

\begin{tabular}{llll}
\hline & Tweets & Followees & Followers \\
\hline Mean & 1152 & 522 & 898 \\
& & & 971 \\
\hline Range & 1789 & 669 & $47-3682$ \\
& & & \\
\hline
\end{tabular}

To get an impression of the reasons for which the journalists use Twitter, we presented them with several statements. Most journalists agreed that they use Twitter to follow the news and to obtain story ideas. However, less agreement was found for our statement that referred to the use of Twitter as a tool to find sources; only half of the journalists said they use Twitter for this purpose. The journalists who were more sceptical about the use of Twitter as a sourcing tool were also less active in the online environment and showed a lower number of tweets and followers.

When discussing these statements more in-depth, the interviews clearly show that Twitter serves at least two major functions as a sourcing tool. First of all, Twitter has the function of an awareness system. The journalists indicated they use Twitter to create their own stream of information and stay up-to-date with trending topics. One journalist explained that Twitter influences their sourcing practices in an indirect way: "We do not report what Twitter writes. It is a source of ideas" (journalist 12). In addition to merely the facts and news events, an important feature of social media is that they also carry the immediate reactions to and opinions about these events. Journalists do not only get an overview of information, which, as some interviewees remarked, can also be provided by press agencies or other information channels, but they can also immediately monitor what the public and the politicians, peers and experts they follow on Twitter think about the news. One journalist compared it with a more traditional way of news gathering and stated: "It is actually a kind of bar where you overhear and pick up everything, but digitally"(10).

The second function we can distinguish relates to Twitter as a trigger. Journalists argue that the social media platform has a genuine signalling function, not just keeping journalists up-to-date but pointing out topics the journalist should look into. In this sense, Twitter can really be at the start of the news gathering process. The idea arises from social media, but when this idea becomes more elaborate, journalists fall back on their traditional sourcing routines. One interviewee described this process as follows: "You see something appear on Twitter and think: 'we can work with this'. And then you pick up your phone"(7). Another journalist backed this idea and explained: "A tweet in itself is never the news. In my case, it is rather an incentive to call a person or ask around what it is about"(8).

In sum, with regard to the role and value of Twitter as a sourcing tool, our findings are consistent with previous research that found that journalists are likely to perceive the social media platform as a useful tool for following the news and for monitoring potential sources in the news discovery phase, rather than for finding or approaching informants in the news gathering phase of the sourcing process. The dominant functions of Twitter can essentially be seen as latent and indirect. The journalists do not often consciously seek out sources or 
information on the platform and when they come across something interesting, their traditional sourcing methods take over. This traditional work routine remains visible in their usage of the online platform. Specific features of Twitter, such as Twitter lists or the direct messaging (DM) feature, are hardly used by most of the journalists we spoke with. A handful of the interviewees said they were subscribed to one or more Twitter lists and mainly referred to the list maintained by the main business newspaper in Flanders. Two journalists said they actively used Twitter lists for news gathering; the others said they just monitor their own timeline. Furthermore, hashtags are sporadically used for specific searches or to follow events or conferences. One journalist specifically mentioned the trending topics on Twitter and said: "I think [it might have] an influence on your output since you can see what is trending on Twitter which makes it easier to assess what is going on"(11). When we discussed their use of DM's on the platform, the preference of traditional sourcing channels remains present. Most of the journalists who work with this function simply use it to get contact information of sources. A journalist that was very enthusiastic about this feature said: "Often I ask via Direct Message: 'Can my colleague give you a call regarding that subject?",'(6). When other contact information is available, this feature becomes less interesting, with one journalist explicitly stating: "I don't think it is very practical, an e-mail works just as well"(1).

\section{Potential vs. actual source networks}

Next to the functions of Twitter within the sourcing process, this study also examines the relations between the networks journalists build online and their actual source network. Therefore, we make the comparison between the potential source networks on Twitter of the interviewed journalists and their actual sourcing behaviour. As explained in the methodology, we collected both the online networks via Twitter and an offline network of one week using the GENSI tool. Both datasets are based on one-degree ego networks starting from the journalist as a central node and studying the (potential) sources this central node is connected to. The following results discuss the quantitative comparison of these two networks by focussing on the actor groups present, but is enriched with qualitative data that illustrate the journalists' perceptions of these networks and actor groups.

In Figure 2 we make a comparison between the size of the group of potential sources on Twitter and the number of actual sources they used recently. We do this on an aggregate level, comparing the entire network of sources of the 33 journalists on Twitter and offline. This gives us a general overview of the relevant source actor groups within economic journalism. Overall, there are significant overlaps between their Twitter networks and their actual sourcing behaviour. In general, business professionals, experts and academics, and interest groups are overrepresented as actually contacted source actors, while media and journalists and ordinary citizens are relatively more present in the potential source networks of journalists. Politicians and government actors have an almost equal share in both the Twitter networks and the contacted source actors.

Media organisations and journalists have a significantly larger presence on Twitter than in the journalists' actual source contacts. This can be explained by the fact that media and especially press agencies are relevant for news discovery and are therefore carefully monitored, but once journalists decide to produce a news story, they will mostly complement the media sources with additional information from other sources. As one journalists commented: "You don't want your newspaper to be filled with all kinds of things that are on the Belga News feed [the Belgian press agency] "(14). The journalists then look for a different angle or in-depth analysis to expand beyond the press releases: "That is also the way in which I use [press agencies] as a source: they bring the news and then I look at how I can expand this"(21). Not only press agencies, but also other media outlets are systematically monitored 
for story ideas and background information. One newspaper journalist mentioned that a day at the newsroom often starts with checking other media: "The first thing we do is look at newspapers to see what our competitors have done. But sometimes it's also a lead"(22). The relative overrepresentation of media sources in the Twitter network can partly be explained by the fact that media actors are closely monitored to stay informed on a wide range of topics, but they are less often used as an explicit source in their own news production. Besides the fact that journalists want to know what their competitors are doing, some interviewees argued that it has more to do with collegiality, considering it obvious to follow their peers and coworkers on Twitter.

Figure 2: The share of different actor groups in the journalists' followee networks on Twitter compared to their share in the journalists' source contacts in the previous week $(\mathbf{N}=33)$

- Share in the journalists' followee list on Twitter $\quad$ Share of actual sources

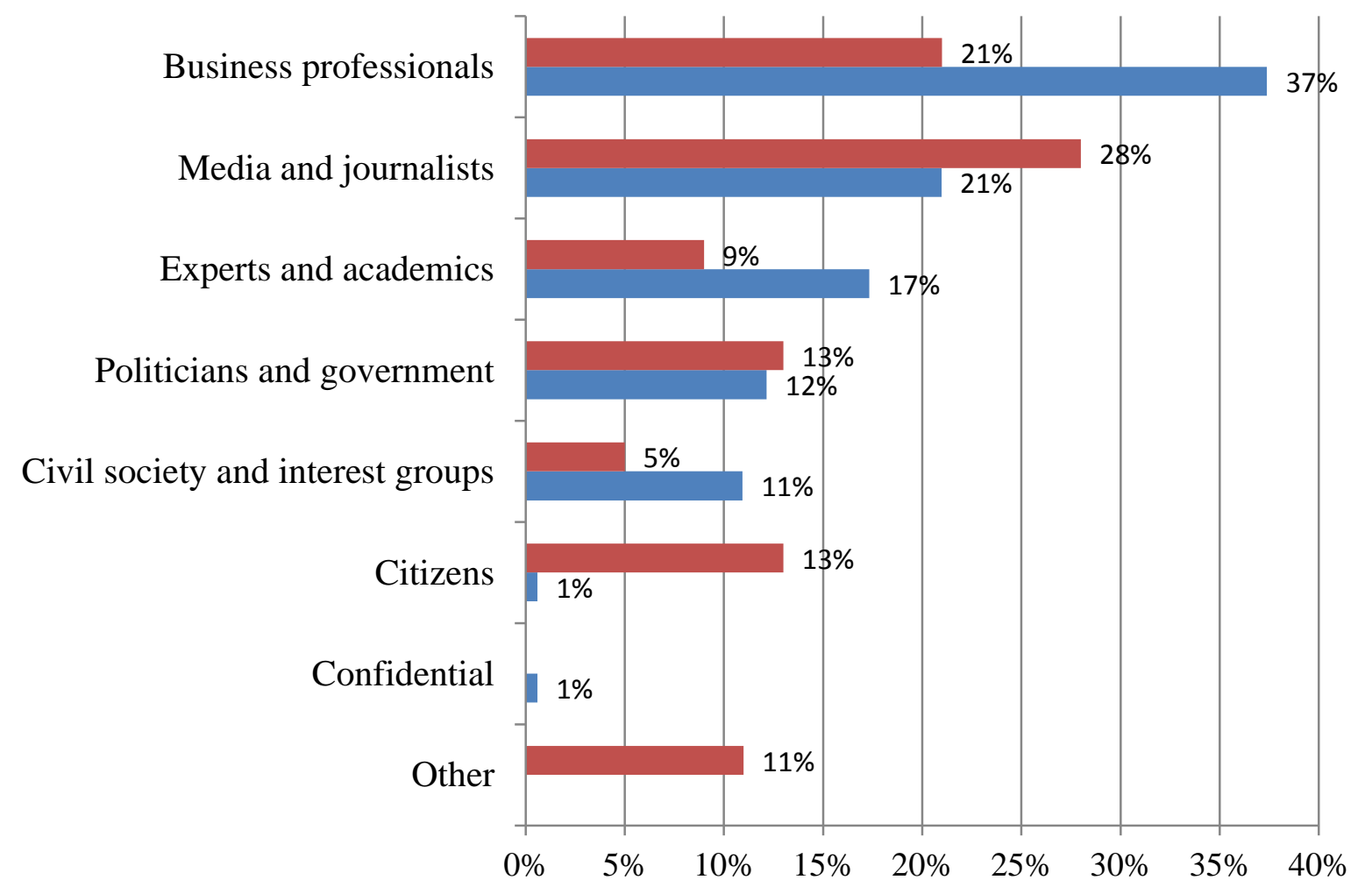

Total number of sources mentioned in the interview: 329; Total number of actors in the Twitter followee networks: 15,894

Business professionals are clearly the most contacted sources according to the journalists we interviewed, occupying 37 percent of the actual source network. We should note that we asked the journalists to mention different sources separately as much as possible. This means that, for example, annual reports of a company, conversations with the CEO of the same company and encounters with their spokesman could all be entered in the GENSI tool as separate sources that trace back to this actor group. Nevertheless, business-related actors are highly present in the actual source network. Economic journalists consider the high presence of this actor group in their source contacts rather obvious because business professionals are usually at the centre of their news stories. One journalist stated it as follows : "Companies? We contact them on a daily basis. They are very important"(30). Compared to the other groups, business professionals are also intensively followed on Twitter: one out of 
five followees in the journalists' Twitter networks (22\%) were identified as business professionals. Yet, their presence is less substantial on the social media platform compared to the actors journalists contacted for background information or as sources in their news reports. A possible explanation is that, while business professionals are often needed as sources in a particular story, they are not, or not necessarily, considered as worthy to follow on a regular basis. A similar pattern can be seen with regard to the actor groups 'experts and academics' and 'civil society and interest groups'. Again, we notice that these actor groups show a higher presence in the actual source network than on Twitter. One journalist explained this as follows: "Experts are less interesting for their newsworthiness but are relevant for comments that distinguish your piece from other media"(21). In other words, they do not regularly bring them new news topics but help them elaborate on new information. Still, we should also recognise that the population of experts, academics, and civil society actors that can be followed on Twitter is rather small compared to other actor groups such as political and business actors.

With a share of 12 percent, the actor group 'politicians and government actors' takes the third position in the list of most contacted actual sources. When discussing the importance of political sources, the journalists said they were particularly interested in actual policy and research done by governmental institutions rather than in political debates. One journalist put it as follows: "The 'political game' doesn't interest me, I want to know what the information is "(5). As Figure 2 shows, the share of source contacts with political actors is similar to the share of this actor group in the Twitter networks of journalists. As opposed to the other source actor groups, citizens are poorly represented in the journalists' actual source contacts. The economic journalist who named two citizens as sources even nuanced the relevance of these source contacts because it was "very specific for this particular story"(20). The journalists said they rarely have contact with citizens and if they do, it is mostly because citizens contact them to comment on an article. Nonetheless, some journalists added that they do have contact with their readers, but not during the sourcing process. As one journalist stated: "Ordinary citizens - I don't know if this falls under the category [of sources] - well, actually we are closely connected to them [because we have] a website that allows comments"(3). Another journalist told us: "Sometimes you receive complaints via e-mail about a company or something else from a citizen and occasionally this leads to something, but most of the time, it doesn't contain a bigger story"(13). One journalists dismissed these sources completely by stating: "I don't consider the use of vox pops a journalistic practice"(5).

In contrast to actual sourcing behaviour, the journalists' Twitter networks show a much larger presence of ordinary citizens. A closer look into our Twitter analysis, however, shows that this is due to a small group of very active Twitter users, as we find a significant effect of the network size on the number of citizens in their network. Nonetheless, according to all journalists in our study, the impact of ordinary citizens as potential sources is small and not perceived very valuable. One journalist said that he just tries to follow people back: "[It has a] public function. It's not the people that give information to me, I give information to them"(1). The citizens in these active networks remain linked to their professional work and do not originate from a private use of the medium. As mentioned above, only two journalists said they also use Twitter for personal purposes. Most of the citizens in journalists' Twitter networks are not friends or relatives, but people with interesting or strong opinions. As one journalist stated: "Twitter remains a professional medium. In my group of friends I don't know a lot of people that use Twitter"(6). Altogether, we see a lot of similarities between the economic journalists' actual source networks and their Twitter networks. The differences we found may be attributed to the role of Twitter in the news production process. The very high presence of media is in line with the use of Twitter as an awareness system, as is the smaller 
role of experts who do not regularly offer story ideas or news topics but make themselves newsworthy through comments and observations.

When discussing the sources journalists used in the previous week, we also asked follow-up questions regarding how they contact or follow these different sources. Table 2 shows the 325 sources categorized into actor groups ${ }^{3}$ divided by the type of contact and whether or not journalists follow them on Twitter. As opposed to the comparison on an aggregated level as presented in Figure 2, Table 2 allows a more individual and in-depth assessment of which of the sources the journalists contacted are actually followed on social media. In general, more than half $(58 \%)$ of the sources are not followed on Twitter. This means that the journalists in our sample did follow 42 percent of the source actors they contacted in the week prior to the interview. The ratio of sources the journalist follows is significantly correlated with his/her number of tweets, followees and followers (respectively $\mathrm{r}=.440 ; \mathrm{p}=.01 ; \mathrm{r}=.472 ; \mathrm{p}=.006 ; \mathrm{r}=.463 ; \mathrm{p}=.007)$. Journalists with an active Twitter profile were more likely to have the source actors they contacted included in their following list on Twitter. As shown in Table 2, media organisations and journalists are heavily followed $(64 \%)$. Within the other actor groups, there is an opposite pattern, especially in the group of business professionals. As mentioned above, these sources are considered extremely relevant in their articles, but seem less worthy to be added as potential sources in the journalists' online information stream. All the other actor groups show an average following of approximately 40 percent.

Table 2: The type of source contact and the number of actual sources followed on Twitter, divided by actor group $(\mathrm{N}=325)$

\begin{tabular}{ccccc}
\hline \multirow{2}{*}{ Actor group } & Follow & Not follow & $\begin{array}{c}\text { Type of source contact } \\
\text { Bnformation }\end{array}$ & $\begin{array}{c}\text { Source cited } \\
\text { in the news }\end{array}$ \\
\cline { 2 - 5 } Media and journalists & $64 \%$ & $36 \%$ & $67 \%$ & $33 \%$ \\
\hline $\begin{array}{c}\text { Politicians and } \\
\text { government }\end{array}$ & $40 \%$ & $60 \%$ & $28 \%$ & $72 \%$ \\
\hline $\begin{array}{c}\text { Business } \\
\text { professionals }\end{array}$ & $30 \%$ & $70 \%$ & $29 \%$ & $71 \%$ \\
\hline $\begin{array}{c}\text { Experts and } \\
\text { academics }\end{array}$ & $44 \%$ & $56 \%$ & $40 \%$ & $60 \%$ \\
\hline $\begin{array}{c}\text { Civil society and } \\
\text { interest groups }\end{array}$ & $42 \%$ & $58 \%$ & $50 \%$ & $50 \%$ \\
\hline Total & $42 \%$ & $58 \%$ & $41 \%$ & $59 \%$ \\
\hline
\end{tabular}

Correlations: actor group $x$ Twitter relation: $\chi^{2}(4)=20.719 ; p<0.001$; actor group $x$ type of source contact: $\chi^{2}(4)=29.550 ; p<0.001$

If we compare the sources quoted in the news to sources that are only used for background information, Table 2 shows that almost half of the sources are solely used for background information. Business professionals are the most used sources in the news, with only 28 percent of them solely providing background information. Although the number of political sources is lower, the ratio is similar with more sources in the news. Media and journalists are more likely to be used for background information rather than as a direct source in news stories. 
Source actors who only provide background information occur slightly more often in the journalists' Twitter network than do source actors who are cited in the news stories (Cramer's V=.149; $\mathrm{p}=0.007$ ). We find an even stronger correlation between the sources that are followed on Twitter and the frequency of contact with these sources (Cramer's V=.301; $\mathrm{p}<0.001)$. The sources that are contacted regularly appear more often in the journalists' Twitter networks of potential sources than sources for whom the frequency of contact is low. Again, this supports the idea that Twitter functions as an awareness system that is especially useful for monitoring sources who can provide ideas and background information.

\section{Conclusion}

Social media have become an important information channel for journalists. In line with previous research on other types of journalists we show that a majority of economic journalists use Twitter for researching purposes, implementing it in their daily routine as a monitoring tool to track relevant information and valuable insights. Journalists become aware of potential news items and pick up on trends on social media. The platform is less used to approach or contact source actors during what Reich (2009) calls the news gathering phase of the production process. During this second phase, other more traditional sourcing channels are employed, even if the initial idea originated from Twitter. Therefore, it is important not to confuse journalists' latent Twitter practices with their actual sourcing practices.

In this study, we compared these two sourcing practices using an innovative methodological approach in combining online social network data with interview data on sourcing practices. Media and journalists are regularly consulted for economic news coverage but display an even higher presence in the Twitter networks of economic journalists, which stresses the monitoring function of Twitter. Business professionals and, to a lesser extent, experts are also actively followed in the online environment but are even more prevalent in their actual sourcing behaviour. In line with previous research on news gathering in economic journalism, the financial elites are dominant in the actual sourcing behaviour of journalists. The stable influence of these actor groups might even lead to more attention towards their online output in the entire stream of information, despite being less established on Twitter. Civil society actors, such as unions and employers' organisations, display a similar pattern of partial overlap, but both in actual sourcing behaviour and in the online network their presence remains relatively low. Political actors show no significant differences between their presence online and their presence in the sources contacted by the journalists.

Although we did not expect citizens to play an important role, it is still remarkable that citizens turn out to be totally irrelevant as sources. Even the moderate presence of citizens in certain Twitter networks (with 13\% citizens overall) does not change this matter. They are seldom considered as a source of inspiration or as an indication of public concerns in the discovery phase and they are completely ignored in the news gathering phase. Our results show that we have to nuance the optimistic idea that Twitter could have a positive influence on the elite bias in journalistic sourcing. At least for sourcing practices of economic journalists of the written press, citizens hardly matter.

The analysis of the overlap between the different actor groups is mainly discussed on the aggregate level. The overlap between the two networks, however, is to a certain extent confirmed when we approach this question from an individual level. Of the sources that journalists contacted in the week prior to the interview, 42 percent is followed on Twitter. The activeness on Twitter affects this measure, with more active Twitter users showing a larger overlap between their actual sourcing behaviour and their following behaviour on Twitter.

Our research focussed on economic journalists where previous research shows us a specific sourcing pattern with a strong elite bias. When we take this into consideration, our 
results are not surprising and show that economic journalists strongly rely on a network of elite sources containing business professionals, experts and political actors. These source actors can largely be found in their Twitter networks. Nevertheless, this study shows that the presence of non-elite actors, and more specifically citizens, on Twitter does not appear to be a turning point within economic sourcing practices, as their influence on the actual news gathering appears insignificant. Citizens are at best potential sources in the Twitter networks of a small group of highly active Twitter users. A minor impact of non-elite potential sources might be present during the discovery of news, yet they are still struggling to pass the rigorous gates of economic journalists. Twitter is used as a tool that has been implemented within and normalised to existing sourcing practices (see Lasorsa, Lewis and Holton 2012), rather than that it seems capable of drastically changing the production process of economic news. This conclusion leads to two questions that need to be tested in further research. First, whether the same irrelevance of citizens as news sources applies to other news beats. At least, our finding is in line with the study by Deprez and Van Leuven (2017) on health journalists, but we might expect for instance political journalists to be more open to citizen input. For political news, the opinions of ordinary citizens might be seen as an alternative indicator of public opinion. More comparative studies, across news beats, are necessary to improve our insights of these differences. Second, if economic journalists do not use Twitter to be informed about ordinary citizens, this raises the question whether they have other sources of public opinion or rather neglect the public at large in their journalistic work. Our study was not really focussed on this question, but might inspire others to dig deeper into this important issue.

\section{DISCLOSURE STATEMENT}

No potential conflicts of interest were reported by the authors.

\section{FUNDING}

This study was supported by the Research Foundation - Flanders (FWO) [grant number G032614N].

\section{NOTES}

1. The results discussed in this paper, both from the Twitter study and the interview data, contain information on the 33 journalists we interviewed. Although we exclude the Twitter data of the journalists we did not interview, there are no significant differences between these two groups regarding number of tweets, followers and followees.

2. Due to a technical issue within NodeXL the number of followees was restricted to 2,000 profiles per journalist, not incorporating the remaining followees. In our sample, two journalists exceeded this limit. When discussing the actor groups in Figure 2, we use the 15,894 followees gathered and coded via NodeXL. The actual number of tweets, followees and followers on their Twitter profile by the end of the data collection was also obtained to assess their overall online behaviour (see Table 1).

3. The 'citizens' category was not used for this analysis because it only contained two sources.

\section{REFERENCES}

Berry, Mike. 2013. “The Today Programme and the Banking Crisis.” Journalism 14 (2): 253270. 
Brems, Cara, Martina Temmerman, Todd Graham, and Marcel Broersma. 2016. "Personal Branding on Twitter: How Employed and Freelance Journalists Stage Themselves on Social Media." Digital Journalism 5 (4): 443-459.

Broersma, Marcel and Todd Graham. 2012. "Social Media as Beat." Journalism Practice 6 (3): 403-419 doi: 10.1080/17512786.2012.663626

Broersma, Marcel, and Todd Graham. 2013. "Twitter as a News Source: How Dutch and British Newspapers Used Tweets in Their News Coverage, 2007-2011.” Journalism Practice 7 (4): 446-464.

Broersma, Marcel, and Todd Graham. 2016. "Tipping the Balance of Power. Social media and the Transformation of Political Journalism." In The Routledge Companion to Social Media and Politics, edited by Axel Bruns, Gunn Enli, Eli Skogerbø, Anders Olof Larsson, and Christian Christensen, 89-103. Abingdon: Routledge.

Deprez, Annelore, Peter Mechant, and Tim Hoebeke. 2013. "Social Media and Flemish Sports Reporters: A Multimethod Analysis of Twitter Use as Journalistic Tool." International Journal of Sport Communication 6 (2): 107-119.

Deprez, Annelore, and Sarah Van Leuven. (2017). "About Pseudo-Quarrels and Trustworthiness. A Multi-Method Study of Health Journalism, Sourcing Practices and Twitter." Journalism $\quad$ Studies $\quad 19(9)$ : $1257-1274$ http://dx.doi.org/10.1080/1461670X.2016.1266910.

Doyle, Gillian. 2006. "Financial News Journalism A Post-Enron Analysis of Approaches Towards Economic and Financial News Production in the UK." Journalism 7 (4): 433452.

Durham, Frank D. 2007. "Framing the State in Globalization: The Financial Times' Coverage of the 1997 Thai Currency Crisis." Critical Studies in Media Communication 24 (1): $57-76$.

Ekström, Mats. 2002. "Epistemologies of TV Journalism.” Journalism 3 (3): 259-282

Ettema, James S. and Theodore L. Glasser. 1985. "On the Epistemology of Investigative Journalism." Communication 8 (2): 183-206.

Gans, Herbert J. 1979. Deciding what's news: A study of CBS evening news, NBC nightly news, Newsweek and Time. New York: Pantheon

Gulyás, Ágnes. 2013. “The Influence of Professional Variables on Journalists' Uses and Views of Social Media." Digital Journalism 1 (2): 270-285.

Gulyás, Ágnes. 2017. "Social Media and Journalism: Hybridity, convergence, changing relationship with the audience, and fragmentation." in The Routledge Companion to Digital Journalism Studies, edited by Bob Franklin and Scott A. Eldridge II, 396-406. Abingdon: Routledge.

Hedman, Ulrika, and Monika Djerf-Pierre. 2013. "The Social Journalist: Embracing the Social Media Life or Creating a New Digital Divide?" Digital Journalism 1 (3): 368385 .

Hedman, Ulrika, and Monika Djerf-Pierre. 2017. "Journalists' Use of Twitter." In The Routledge Companion to Digital Journalism Studies, edited by Bob Franklin and Scott A. Eldridge II, 417-426. Abingdon: Routledge.

Hermida, Alfred. 2010. "Twittering the News: The Emergence of Ambient Journalism." Journalism Practice 4 (7): 297-308.

Hladík, Radim, and Václav Štětka. 2017. "The powers that tweet: Social media as news sources in the Czech Republic." Journalism Studies 18 (2): 154-174.

Kalogeropoulos, Antonis, Erik Albæk, Claes De Vreese, and Arjen Van Dalen. 2015. "The Predictors of Economic Sophistication: Media, Interpersonal Communication and Negative Economic Experiences." European Journal of Communication 30 (4): 385403. 
Kalogeropoulos, Antonis, Helle Mølgaard Svensson, Arjen Van Dalen, Claes De Vreese, and Erik Albæk. 2015. "Are Watchdogs Doing Their Business? Media Coverage of Economic News." Journalism: Theory, Practice \& Criticism 16 (8): 993-1009.

Kjær, Peter, and Tore Slaatta. 2007. "Mediating Business: Toward a Relational Perspective" In Mediating Business: The Expansion of Business Journalism, edited by Peter Kjær and Tore Slaatta, 13-35. Copenhagen: Copenhagen Business School Press.

Knowles, Sophie, Gail Philips, and Johan Lindberg. 2017. "Reporting The Global Financial Crisis: A Longitudinal Tri-Nation Study of Mainstream Financial Journalism." Journalism Studies 18 (3): 322-340.

Lariscy, Ruthann Weaver, Elizabeth Johnson Avery, Kaye D. Sweetser, and Pauline Howes. 2009. "An Examination Of the Role of Online Social Media in Journalists' Source Mix." Public Relations Review 35 (3): 314-316.

Lasorsa, Dominic L., Seth C. Lewis, and Avery E. Holton. 2012. "Normalizing Twitter." Journalism Studies. 13 (1): 19 - 36.

Lawrence, Regina G., Logan Molyneux, Mark Coddington, and Avery Holton. 2014. “Tweeting Conventions." Journalism Studies 15 (6): 789-806.

Lecheler, Sophie, and Sanne Kruikemeier. 2016. "Re-Evaluating Journalistic Routines in a Digital Age: A Review of Research on the Use of Online Sources." New media \& Society 18 (1): $156-171$.

Lee, Micky. 2014. "A Review of Communication Scholarschip on the Financial Markets and the Financial Media since the 1980's." International Journal of Communication 8 (1): 715-736.

Manning, Paul. 2013. "Financial Journalism, News Sources and the Banking Crisis." Journalism 14 (2): 173-189.

Parmelee, John H. 2013. "Political Journalists and Twitter: Influences on Norms and Practices." Journal of Media Practice 14 (4): 291-305.

Paulussen, Steve, and Raymond A. Harder. 2014. "Social Media References in Newspapers: Facebook, Twitter and YouTube as Sources in Newspaper Journalism." Journalism Practice 8 (5): 542-551.

Raeymaeckers, Karin, Annelore Deprez, Sara De Vuyst, and Rebeca De Dobbelaer. 2015. "The Journalist As a Jack of All Trades." In Gatekeeping in Transition, edited by Tim P. Vos and François Heinderyckx, 104 - 119. New York: Routledge.

Reich, Zvi. 2009. Sourcing the news. Cresskill, NJ: Hampton Court.

Reich, Zvi, and Aviv Barnoy. 2016. "Reconstructing Production Practices Through Interviewing" In The Sage Handbook of Digital Journalism, edited by Tamara Witschge, C.W. Anderson, David Domingo and Alfred Hermida, 477 - 493. London: Sage.

Schifferes, Steve and Stephen Coulter. 2013. "Downloading Disaster: BBC News Online Coverage of the Global Financial Crisis." Journalism 14 (2): 228-252.

Schiffrin, Anya. 2015. "The Press and the Financial Crisis: A Review of the Literature." Sociology Compass 9 (8): 639-653.

Sigal, Leon V. 1973. Reporters and Officials: The Organization and Politics of Newsmaking. Lexington, Mass: DC Heath.

Sigal, Leon V. 1999. "Reporters and Officials: The Organization and Politics of Newsmaking." In News: A Reader, edited by Howard Tumber, 224 - 234. Oxford: Oxford University Press.

Stark, Tobias H., and Jon A. Krosnick. 2017. "GENSI: A New Graphical Tool to Collect EgoCentered Network Data." Social Network 48: 36-45.

Tambini, Damian. 2010. "What Are Financial Journalists For?" Journalism studies 11 (2): 158-174. 
Tandoc, Edson C., and Tim P. Vos. 2016. "The Journalist Is Marketing the News." Journalism Practice 10 (8): 950-966.

Van Leuven, Sarah, and Annelore Deprez. 2017. "To Follow or not to Follow? How Belgian Health Journalists Use Twitter to Monitor Potential Sources." Journal of Applied Journalism and Media Studies 6 (3): 545-566. doi:10.1386/ajms.6.3.545_1

Zeller, Frauke, and Alfred Hermida. 2015. "When Tradition Meets Immediacy and Interaction. The Integration of Social Media in Journalists' Everyday Practices." Sur le Journalisme, About Journalism, Sobre Jornalismo 4 (1): 106-119.

\section{APPENDIX}

List of journalists

\begin{tabular}{|c|c|c|c|c|}
\hline & Tweets & Followees & Followers & Employer \\
\hline Journalist 1 & 7784 & 3241 & 3682 & Economic newspaper \\
\hline Journalist 2 & 5773 & 1459 & 2075 & Economic newspaper \\
\hline Journalist 3 & 3969 & 405 & 1427 & Economic newspaper \\
\hline Journalist 4 & 3680 & 2061 & 2571 & Economic magazine \\
\hline Journalist 5 & 2507 & 231 & 3008 & Economic newspaper \\
\hline Journalist 6 & 1851 & 781 & 1856 & Economic newspaper \\
\hline Journalist 7 & 1769 & 110 & 2077 & General newspaper \\
\hline Journalist 8 & 1527 & 1091 & 1743 & Economic newspaper \\
\hline Journalist 9 & 1339 & 549 & 752 & Economic newspaper \\
\hline Journalist 10 & 1179 & 770 & 526 & Economic newspaper \\
\hline Journalist 11 & 1053 & 632 & 1067 & Economic magazine \\
\hline Journalist 12 & 990 & 189 & 1719 & Economic magazine \\
\hline Journalist 13 & 868 & 299 & 1668 & General newspaper \\
\hline Journalist 14 & 698 & 871 & 794 & General newspaper \\
\hline Journalist 15 & 690 & 208 & 202 & Economic newspaper \\
\hline Journalist 16 & 568 & 703 & 459 & Economic magazine \\
\hline Journalist 17 & 463 & 842 & 304 & Economic magazine \\
\hline Journalist 18 & 418 & 731 & 997 & Economic magazine \\
\hline Journalist 19 & 204 & 229 & 573 & Economic magazine \\
\hline Journalist 20 & 180 & 63 & 187 & Freelance \\
\hline Journalist 21 & 174 & 195 & 91 & Economic website \\
\hline Journalist 22 & 141 & 110 & 267 & Economic newspaper \\
\hline Journalist 23 & 43 & 263 & 166 & Economic magazine \\
\hline Journalist 24 & 42 & 73 & 95 & Economic magazine \\
\hline Journalist 25 & 28 & 161 & 110 & Economic newspaper \\
\hline Journalist 26 & 19 & 417 & 150 & General newspaper \\
\hline Journalist 27 & 17 & 118 & 215 & General newspaper \\
\hline Journalist 28 & 15 & 39 & 47 & Economic magazine \\
\hline Journalist 29 & 12 & 83 & 176 & Economic magazine \\
\hline Journalist 30 & 5 & 51 & 245 & General newspaper \\
\hline Journalist 31 & 3 & 133 & 95 & Economic magazine \\
\hline Journalist 32 & 2 & 93 & 106 & General newspaper \\
\hline Journalist 33 & 0 & 24 & 170 & Economic newspaper \\
\hline
\end{tabular}

